\title{
Why Family Caregivers Choose to Institutionalize a Loved One with Dementia: A Singapore Perspective
}

\author{
Chee Wee Tew ${ }^{a}$ Li Feng Tan ${ }^{b}$ Nan Luoc, d Wai Yee $\mathrm{Ng}^{c}$ Philip Yap ${ }^{a}$ \\ ${ }^{a}$ Department of Geriatric Medicine, Khoo Teck Puat Hospital, Alexandra Health, ${ }^{b}$ Yong Loo Lin School of Medicine, \\ ${ }^{c}$ Department of Epidemiology and Public Health, Yong Loo Lin School of Medicine, and ${ }^{d}$ Centre for Health Services \\ Research, Yong Loo Lin School of Medicine, National University of Singapore, Singapore
}

\section{Key Words}

Caregiver burden - Caregiver gain - Caregivers .

Dementia • Foreign domestic worker - Institutionalization • Intervention $\cdot$ Nursing home $\cdot$ Risk factors

\begin{abstract}
Aim: To examine factors associated with family caregivers' choice of care setting (own home vs. nursing home) for their relatives with dementia. Methods: Cross-sectional study involving caregivers recruited from a tertiary hospital dementia clinic and the local Alzheimer's association. Caregivers completed a questionnaire containing demographics of the person with dementia (PWD) and caregiver, their choice of care setting and the following scales: Gain in Alzheimer Care Instrument, General Health Questionnaire, Short Sense of Competence Questionnaire, Revised Memory and Behavioral Problems Checklist and Zarit Burden Interview. Multiple logistic regression was performed to identify significant variables associated with the outcome of interest. Results: The final sample comprised 266 caregivers, the majority of whom were Chinese, female and children of PWD. Most ( $85.7 \%$ ) preferred care at home, only 38 (14.3\%) chose institutionalization. Four factors were associated with choice of nursing home: caregiver working $(\mathrm{OR}=6.363,2.120-19.086)$, no domestic maid $(\mathrm{OR}=3.27,1.458-7.331)$, lower caregiver gain
\end{abstract}

$(\mathrm{OR}=0.935,0.882-0.992)$ and behavioral problems in PWD $(\mathrm{OR}=1.011,1.005-1.018)$. Conclusion: Strategies to minimize institutionalization must first address the provision of a dedicated caregiver at home. Consequently, interventions to help caregivers cope with behavioral problems in PWD and enhance caregiver gain are relevant.

Copyright $\odot 2011$ S. Karger AG, Basel

\section{Introduction}

Dementia is a well-recognized global issue with the number of persons affected growing exponentially, particularly in the Asia-Pacific region. Previous epidemiologic studies have estimated a prevalence of 24.3 million cases worldwide with 4.6 million new cases each year [1]. Disproportionately high rates with a more than $300 \%$ increase are expected between 2001 and 2040 in India and China, as well as their South Asian and Western Pacific neighbors. A report by the Asia Pacific members of Alzheimer's Disease International has predicted the prevalence of dementia in Singapore to increase from 22,000 in 2005 to 53,600 in 2020 and 186,900 in 2050 [2].

The ageing phenomenon, epitomized by dementia, coincides with a declining number of family members available to care for ageing parents due to shrinking fam-

\section{KARGER}

Fax +4161306 1234

E-Mail karger@karger.ch

www.karger.com
(C) 2011 S. Karger AG, Basel

$1420-8008 / 10 / 0306-0509 \$ 26.00 / 0$

Accessible online at:

www.karger.com/dem
Dr. Chee Wee Tew

Department of Geriatric Medicine, Khoo Teck Puat Hospital

Alexandra Health, Singapore, 90 Yishun Central

Singapore 768828 (Singapore)

Tel. +65 6555 8000, Fax +65 6602 3700, E-Mail tew.chee.wee@alexandrahealth.com.sg 
ily units and a growing trend towards dual-income families, where husbands and wives both hold jobs. Consequently, there is an anticipated increase in demand for long-term institutional care. While efforts are made to expand nursing home capacity in Singapore by $50 \%$ over the next decade from 9,200 to 14,000 [3], it is accepted wisdom in our country to let older persons retire in the comfort of their own homes and for the family to continue to be the primary caregiving resource. Moreover, studies have shown that older persons prefer to live at home in order to maintain their social networks and links with the community [4], thereby enabling a better quality of life. To meet the competing demands of work and caring for one's parents, many Singaporeans employ foreign domestic maids to care for their ageing parents [5]. This unique caregiving arrangement presents an opportunity to study the effects of domestic maids on caregiving outcomes.

Extant literature has shown that the decision to institutionalize a person with dementia (PWD) is often complex and involves interaction between PWD and caregiver factors, as well as contextual factors relating to the caregiving situation [6]. While caregiver characteristics associated with nursing home placement of PWD have been previously explored $[7,8]$, few studies have evaluated the decision-making process from the caregivers' perspective. In Asian societies, children are traditionally bound by duty to care for their ageing parents. Admitting one's parents to a nursing home generally receives disapproval and is perceived as a failure of filial duty. Similarly, in oriental culture, spouses, especially wives, are expected to care for their partner right to the end and failure to do so can be seen as a breach of spousal fidelity.

Against this sociocultural backdrop, it would be appropriate to surmise that family members who choose to institutionalize a PWD must do so under extenuating circumstances. It is therefore highly pertinent to investigate the reasons behind the caregivers' decision. A caregiver's preference for institutionalization has been shown to be a strong predictor of eventual nursing home placement $[8,9]$. The aim of this study is to investigate the factors associated with family caregivers' choice of where (own home vs. nursing home) to care for a relative with dementia.

In addition, much has been published about the stress and burden of dementia caregiving and its predisposition to institutionalization. Caregiver interventions have thus been largely targeted at alleviating burden and improving coping strategies. However, caring for a close relative with dementia can also bring about positive outcomes such as personal and spiritual growth, feelings of mastery and strengthened relationships $[10,11]$. Positive appraisal in caregiving can coexist with burden and help buffer the ill-effects of burden [12]. We hypothesize that burden increases the odds of a caregiver's preference to institutionalize a relative with dementia whereas caregiver gain exerts a protective effect.

\section{Methods}

\section{Subjects and Procedure}

This study was part of a larger study, the Singapore Dementia Caregiver Profile Study, funded by the local National Council of Social Service. The Domain Specific Review Board of the National Healthcare Group Singapore granted ethical approval for the study. A consecutive sample of family caregivers was obtained from 2 sources: the ambulatory dementia clinic of a tertiary hospital (Alexandra Hospital) and the local Alzheimer's association (Alzheimer's Association of Singapore). We selected subjects from these 2 organizations because they are similar in the type and range of support programs and services provided for caregivers and PWD.

For Alexandra Hospital, caregivers visiting the clinic with the PWD were invited to participate in the study, whereas for the Alzheimer's association, the caregivers were contacted through the clients' registry. The patients (PWD) in both sites had been diagnosed as suffering from dementia by clinicians (psychiatrists, geriatricians and neurologists) with established clinical criteria, such as the Diagnostic Manual of Mental Disorders, 4th edition [13].

The investigator explained the nature and aims of the study, and the voluntary and confidential nature of participation. This information was also provided via a participant information sheet. Those who consented to the study signed an informed consent form. Inclusion criteria comprised: (1) literacy in English or Mandarin and ability to complete a survey questionnaire and (2) a family member aged $\geq 18$ years providing care or assistance to a relative with dementia for at least 6 months. Providing care could mean attending to the needs of the PWD, going to doctor's appointments with him, helping him take medication, helping with housework or cooking, helping him bathe or dress, providing emotional support, spending time talking to him, taking him on outings, etc.

For this particular study, we selected only main caregivers who were caring for the PWD in his own home at the time of the study. We defined main caregivers as family members with the primary responsibility of decision-making and care for the wellbeing of the PWD. In our country, it is common for family members to work and employ a foreign domestic maid to attend to the daily needs of the PWD. In these instances, the maid was not considered the main caregiver as she was neither a family member nor carried the primary responsibility for decision-making and the well-being of the PWD.

Even though the study questionnaire was to be completed independently, the subjects were first given an explanation and summary of the questionnaire by the investigator. Identical English and Chinese versions of the questionnaire were prepared for subjects to choose at their own preference. Subjects could com- 
plete the questionnaire on- or off-site; if the latter, they would return the questionnaire by mail. The majority of the subjects returned the questionnaire within 10 days. Those who did not return the questionnaire after 2 weeks were reminded by telephone. Data collection started on June 2, 2008 and ended on February 28, 2009.

\section{Measures}

The study questionnaire obtained data on the demographic characteristics of the family caregivers including age, gender, ethnicity, education, relationship to the PWD and housing type as a surrogate marker of socioeconomic status. Information on the situational factors related to caregiving comprised duration of caregiving; living arrangements; whether the caregiver was holding a regular job, received help from a domestic maid or the utilized dementia support services such as day care; and if the caregiver attended educational or support programs in dementia care. The primary study outcome was assessed by a question with a dichotomous response on whether the caregiver preferred to continue to care for the PWD in his own home or the nursing home.

Information obtained on the PWD included age, gender and stage of dementia as assessed by the Diagnostic Manual of Mental Disorders, 3rd edition (DSM IIIR) [14]. There are 3 levels of severity (mild, moderate and severe) defined by DSM IIIR and descriptors are provided for each level of severity. Respondents were asked to choose the most appropriate descriptor for the PWD. The following standardized measures were included in the survey questionnaire.

\section{Gains in Alzheimer Care Instrument}

The Gains in Alzheimer Care Instrument (GAIN) is a new scale developed to measure gains in dementia caregiving from the perspective of the family caregiver [11]. The scale comprises 3 components measured by 10 items phrased as positive statements. The components are: (1) personal growth (patience, strength, selfawareness and knowledge), (2) gains in relationships (closer to PWD, family members and relate better to older people) and (3) higher-level gains (positive change in life philosophy, spiritual growth and altruism). A Likert scale from 0 (disagree a lot) to 4 (agree a lot) is applied to each item and all items are summed to generate a total score that ranges from 0 to 40 , with higher scores indicating higher gains. The measure demonstrated good psychometric properties in a recent validation study [15]. We employed this scale because it was developed from qualitative in-depth interviews and grounded in the actual experience of caregivers in our Asian population.

\section{General Health Questionnaire-28}

The General Health Questionnaire (GHQ) has been widely used and validated as a screening tool for general psychiatric morbidity in the community. The version used in this study was the 28-item questionnaire (GHQ-28) [16]. There are 4 subscales, each with 7 items: subscale A for somatic symptoms, subscale B for anxiety and insomnia, subscale $\mathrm{C}$ for social dysfunction and subscale D for severe depression. Out of 28 items, 7 items are formulated in a positive manner and 21 items are formulated in a negative manner. The total possible score ranges from 0 to 84 with higher scores denoting poorer well-being. The GHQ-28 had been used in a previous study in Singapore [17].

Why Family Caregivers Choose to

Institutionalise a Loved One with Dementia?

\section{Zarit Burden Interview}

The 22-item Zarit Burden Interview (ZBI) [18] assesses the level of burden experienced by the caregivers. Both objective and subjective burden are assessed by the scale items covering the domains, which include financial difficulties, social life, physical and psychological health, and the relationship between the PWD and the caregiver. Each item is rated on a 5-point scale, ranging from 0 (never) to 4 (nearly always). A total burden score is obtained by adding the responses to the individual items, with higher scores reflecting greater caregiver burden. The ZBI was validated in Singapore in a previous study [19].

\section{Short Sense of Competence Questionnaire}

The Short Sense of Competence Questionnaire (SSCQ) is a brief 7-item measure that assesses a caregiver's self-efficacy in dementia caregiving [20]. It comprises 3 domains that measure satisfaction with the PWD as a recipient of care, satisfaction with one's performance as a caregiver, and the effects of caregiving on the personal life of the caregiver. The score range is from 0 to 7 , with higher scores suggesting higher levels of self-perceived competence.

\section{Revised Memory and Behavior Problems Checklist}

The 24-item Revised Memory and Behavior Problems Checklist (RMBPC) [21] assesses the frequency of PWD behavioral problems as well as the caregivers' reactions to each problem. Ratings are made on a 5-point scale for frequency of problem behaviors ( $0=$ never occurred, $4=$ occurred daily or more often) and for reactions to each of these problems $(0=$ not at all, $4=$ extremely $)$. The total score is a mathematical product of frequency and reaction, with higher scores reflecting greater severity of the behavioral problems in the PWD as perceived by the caregiver.

Data Analysis

Statistical analysis was performed with SAS software version 9.2 for Windows. The main outcome of interest was the choice of the caregiver with regard to where best to care for the PWD (own home vs. nursing home). The first stage of analysis involved the screening of all variables using univariate analyses (independent $t$ test, ANOVA or $\chi^{2}$ test depending on the measurement of the variable) to identify variables to be used in the regression analysis. Variables that were significant in univariate analyses $(p<0.05)$ were entered into a logistic regression model using the backward variable selection method. This less conservative method of analysis was chosen with the intention of exploring possible variables that may be significantly associated with the outcome of interest.

\section{Results}

\section{Description of Sample}

The questionnaire was given to 442 family caregivers and 340 (76.9\%) were returned at the end of the study. Of the 340 subjects, 268 were main caregivers and the final number of subjects with valid analyzable data for this study was 266 due to incomplete responses (several missing items) from 2 of the subjects. Those who did not return the questionnaire cited problems such as poor eye- 
sight, language difficulties, recent death of the relative with dementia, time constraints and lack of interest. Differences between respondents and nonrespondents could not be examined.

The mean age of the caregivers was 52.6 years (SD 11.1, range 22-85). The majority were Chinese (94.7\%), female (73.6\%), children of the PWD (69.2\%) and had received at least a school high education (88.7\%). Most of them lived with the PWD (79.2\%) and had been providing care for more than 3 years (54.5\%). A significant proportion of them were working $(61.3 \%)$ and received assistance in their caregiving role $(52.8 \%)$ from a foreign domestic maid (table 1).

Most caregivers (85.7\%) preferred to continue looking after the PWD themselves at home, with only $14.3 \%$ opting for nursing home care.

\section{Univariate Analysis on Caregiver's Preference for Site} of Care

Caregivers who opted to enroll the PWD in a nursing home were more likely to be younger, holding a job, not living with the PWD and not assisted by a domestic maid (table 2). These caregivers also had significantly higher levels of burden (ZBI) and mental distress (GHQ), as well as lower positive appraisal of caregiving (GAIN) and selfefficacy (SSCQ).

A higher RMBPC score, denoting more problematic behavior in the PWD, was associated with an increased likelihood of the caregiver choosing the nursing home. The 'memory' subscale had the highest mean score of 25.6 (SD 25.4), followed by the 'disruptive' subscale (14.7, SD 20.2) and the 'depression' subscale (14.3, SD 21.1). The most common behavior was 'forgetting what day it is', while 'asking the same question over and over' caused the greatest distress on caregivers. Dementia severity (DSM IIIR) and whether the PWD attended day care did not significantly impact the caregivers' decision.

\section{Multivariate Analysis on Caregiver's Preference for Site of Care}

Logistic regression (table 3) on the significant variables in univariate analysis showed that caregivers who preferred caring for the PWD in nursing homes to continuing to care for them in their own homes were more likely to be working $(\mathrm{OR}=6.363)$ and more likely not to be assisted in their caregiving role by a domestic maid $(\mathrm{OR}=3.27)$. They were also less likely to appraise the caregiving experience positively with lower GAIN scores $(\mathrm{OR}=0.935)$ and experienced more behavioral problems in the PWD $(\mathrm{OR}=1.011)$.
Table 1. Caregiver characteristics $(\mathrm{n}=266)$

\begin{tabular}{|c|c|c|}
\hline & $\mathrm{n}^{*}$ & $\%$ \\
\hline Mean age, years (SD) & $52.6(11.1)$ & \\
\hline \multicolumn{3}{|l|}{ Gender } \\
\hline Male & 70 & 26.4 \\
\hline Female & 195 & 73.6 \\
\hline \multicolumn{3}{|l|}{ Ethnicity } \\
\hline Chinese & 252 & 94.7 \\
\hline Non-Chinese & 14 & 5.3 \\
\hline \multicolumn{3}{|l|}{ Education } \\
\hline No education/primary & 30 & 11.3 \\
\hline High school/diploma & 166 & 62.4 \\
\hline Tertiary & 70 & 26.3 \\
\hline \multicolumn{3}{|l|}{ Housing } \\
\hline Public (nonexecutive) & 117 & 44.3 \\
\hline Public (executive) & 70 & 26.5 \\
\hline Private & 77 & 29.2 \\
\hline \multicolumn{3}{|l|}{ Relationship with PWD } \\
\hline Spouse & 48 & 18.0 \\
\hline Children & 183 & 69.2 \\
\hline Others & 34 & 12.8 \\
\hline \multicolumn{3}{|l|}{ Living with PWD } \\
\hline Yes & 210 & 79.2 \\
\hline No & 55 & 20.8 \\
\hline \multicolumn{3}{|l|}{ Duration of caregiving } \\
\hline $0.5-3$ years & 120 & 45.5 \\
\hline$>3$ years & 144 & 54.5 \\
\hline \multicolumn{3}{|l|}{ Working (holding a job) } \\
\hline Yes & 163 & 61.3 \\
\hline No & 103 & 38.7 \\
\hline \multicolumn{3}{|l|}{ Domestic maid } \\
\hline Yes & 140 & 52.8 \\
\hline No & 125 & 47.2 \\
\hline
\end{tabular}

* Does not total 266 in some items due to nonresponse from the subjects.

\section{Discussion}

The study results indicate most caregivers preferred caring for a relative with dementia in their own homes to nursing homes. This is possibly a reflection of the fundamental oriental values in our society where filial piety and fidelity are considered among the highest virtues. However, despite the possible stigma associated with placing a family member in the nursing home, a modest number of 38 caregivers (14.3\%) openly expressed this desire. Exploring the factors that predisposed them to their choice can better inform strategies to delay or reduce nursing home admissions.

On multivariate analysis, caregivers who were not holding jobs and who expressed higher caregiving gains 
Table 2. Univariate analysis on caregiver's preference for site of care for PWD

\begin{tabular}{|c|c|c|c|}
\hline & \multicolumn{2}{|l|}{ Number (\%) } & \multirow[t]{2}{*}{$\mathrm{p}$} \\
\hline & $\begin{array}{l}\text { nursing home } \\
228 \text { (85.7) }\end{array}$ & $\begin{array}{l}\text { own home } \\
38(14.3)\end{array}$ & \\
\hline \multicolumn{4}{|l|}{ Caregiver variables } \\
\hline Age group & & & 0.0213 \\
\hline 22-44 years & $15(40.5)$ & $47(20.6)$ & \\
\hline$<45-60$ years & $18(48.7)$ & $132(57.9)$ & \\
\hline$>60$ years & $4(10.8)$ & $49(21.5)$ & \\
\hline Education & & & 0.8084 \\
\hline No education/primary & $5(13.2)$ & $25(11.0)$ & \\
\hline High school/diploma & $21(55.3)$ & $145(63.6)$ & \\
\hline Degree & $12(31.6)$ & $58(25.4)$ & \\
\hline Housing & & & 0.2279 \\
\hline Public (nonexecutive) & $21(55.3)$ & $96(42.5)$ & \\
\hline Public (executive) & $10(26.3)$ & $60(26.6)$ & \\
\hline Private property & $7(18.4)$ & $70(31.0)$ & \\
\hline Relationship with PWD & & & 0.5898 \\
\hline Spouse & $4(10.5)$ & $44(19.3)$ & \\
\hline Children & $28(73.7)$ & $156(68.5)$ & \\
\hline Other & $6(15.8)$ & $28(12.3)$ & \\
\hline Duration of caregiving & & & 0.6739 \\
\hline $0.5-3$ years & $18(48.7)$ & $102(44.9)$ & \\
\hline$>3$ years & $19(51.4)$ & $125(55.1)$ & \\
\hline Living with PWD & & & 0.0021 \\
\hline Yes & $23(60.5)$ & $187(82.4)$ & \\
\hline No & $15(39.5)$ & $40(17.6)$ & \\
\hline Working status & & & 0.0017 \\
\hline Working & $32(84.2)$ & $131(57.5)$ & \\
\hline Not working & $6(15.8)$ & $97(42.5)$ & \\
\hline Domestic maid & & & 0.0130 \\
\hline Yes & $13(34.2)$ & $127(56.0)$ & \\
\hline No & $25(65.8)$ & $100(44.1)$ & \\
\hline Total ZBI score & $44.7 \pm 17.7$ & $34.5 \pm 14.2$ & 0.0001 \\
\hline Total GHQ-28 score & $32.2 \pm 16.1$ & $23.0 \pm 12.6$ & 0.0016 \\
\hline Total GAIN score & $27.3 \pm 6.6$ & $30.8 \pm 6.4$ & 0.0023 \\
\hline Total SSCQ score & $12.6 \pm 6.0$ & $15.2 \pm 6.1$ & 0.0183 \\
\hline \multicolumn{4}{|l|}{$P W D$ variables } \\
\hline Severity of dementia & & & 0.2049 \\
\hline Mild & $10(26.3)$ & $52(23.0)$ & \\
\hline Moderate & $13(34.2)$ & $111(49.1)$ & \\
\hline Advanced & $15(39.5)$ & $63(27.9)$ & \\
\hline Use of dementia day care & & & 0.6888 \\
\hline Yes & $18(47.3)$ & $116(50.9)$ & \\
\hline No & $20(52.6)$ & $112(49.1)$ & \\
\hline RMBPC score & $84.6 \pm 67.3$ & $49.8 \pm 50.9$ & 0.0039 \\
\hline
\end{tabular}

were less likely to choose institutionalization for the PWD, whereas not having the assistance of a domestic maid and increased behavioral problems in the PWD had the opposite effects. Notably, the presence of an in-home caregiver, as implied by the main family caregiver not in
Table 3. Multivariate analysis on caregiver's preference for nursing home

\begin{tabular}{lll}
\hline & Adjusted OR $(95 \% \mathrm{CI})$ & $\mathrm{p}$ \\
\hline $\begin{array}{l}\text { Working status } \\
\quad \text { Not working }\end{array}$ & 1.00 & \\
$\quad$ Working & $6.363(2.120-19.086)$ & \\
Domestic maid & & \\
$\quad$ Yes & 1.00 & 0.0010 \\
$\quad$ No & $3.270(1.458-7.331)$ & \\
Total GAIN score & $0.935(0.882-0.992)$ & 0.0270 \\
Total RMBPC score & $1.011(1.005-1.018)$ & 0.0005 \\
\hline
\end{tabular}

paid employment or having a domestic maid to care for the PWD, demonstrated clear protective effects. This suggests that the fundamental requisite for caring for a PWD in his or her own home is the presence of a dedicated caregiver [22]. On closer scrutiny, the results can mean that the financial resources of the family feature importantly as well [12]. Caregivers who can remain economically viable without having to work and who can stay at home to care for the PWD or afford to employ a domestic maid will be more likely to continue to care for the PWD at home. On the other hand, caregivers who need to work for a livelihood and are unable to afford a domestic maid are driven by circumstances to institutionalize the PWD.

Congruent with the findings of other studies, several measures of caregiver stress were predictive of institutionalization in the univariate analysis, in particular higher caregiver burden (ZBI) and mental distress (GHQ), and lower appraisal of self-competence (SSCQ) [7]. These factors, however, did not remain significant after multivariate analysis, and only caregiver gain showed a significant positive correlation with the decision to continue caring for the PWD at home $(\mathrm{OR}=0.935)$. Concerning patient variables, it was neither the cognitive state of the PWD nor his level of dependency, but the degree of behavioural problems that proved important, which is consistent with the published literature [23]. Behavioral problems related to poor memory such as 'asking the same question over and over', 'losing or misplacing things' and 'trouble remembering recent events', posed the greatest distress on our caregivers. The results of this study suggest that although increased behavioral problems in the PWD raises the likelihood that caregivers may choose to institutionalize the PWD, a commensurate amount of caregiver gain can moderate the effects of these negative factors and exert a protective effect. This 
Fig. 1. Model to explain factors that determine site of care for the PWD. $(+)=$ Increases likelihood; $(-)=$ decreases likelihood.

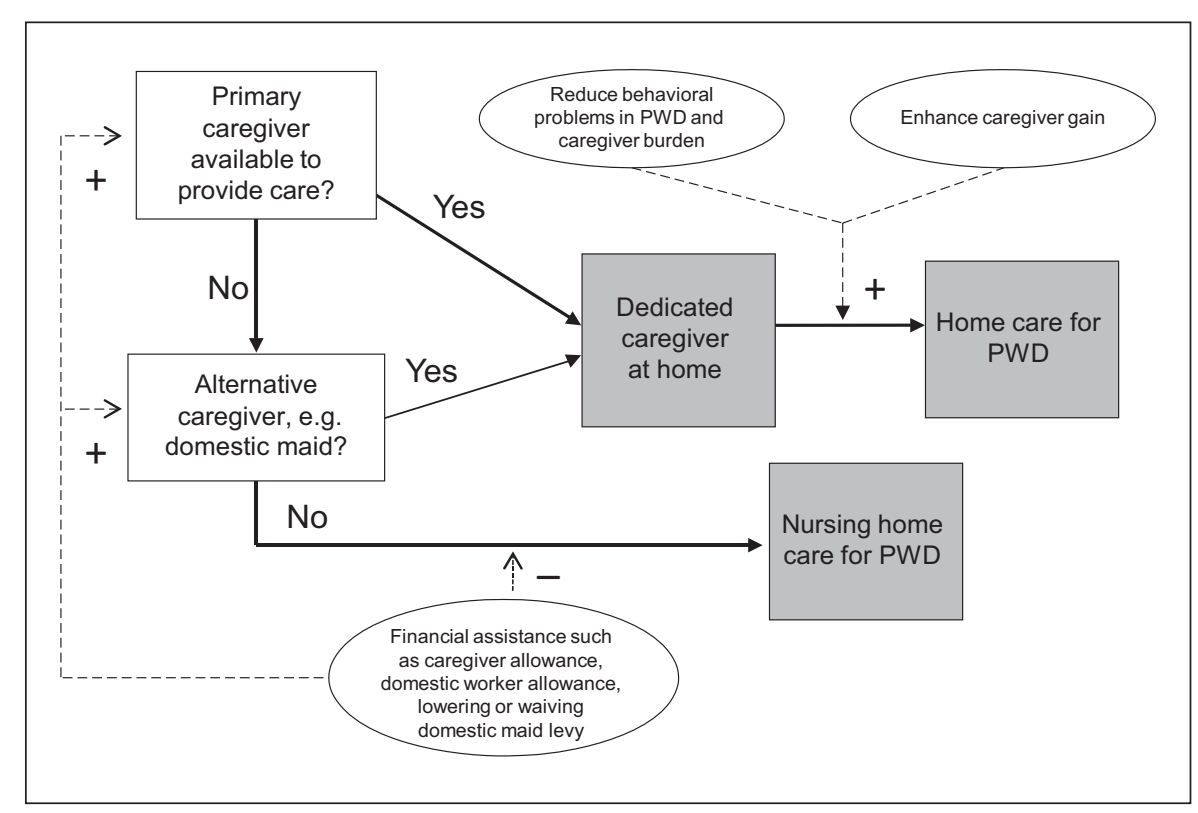

finding consolidates the value of caregiver gain as a target for intervention to improve outcomes in dementia care, and emphasizes the need for further research in this area. This is in line with the current recommendations of employing nonpharmacological interventions first in the management of behavioral problems in dementia, as pharmacological control is only modestly effective and is associated with significant side effects.

Taken together, the study results show that the key to delaying institutionalization lies in fulfilling the fundamental prerequisite of having a caregiver at home, be it a family member or a domestic maid. As such, empowering caregivers with tangible assistance in the form of financial aid can be useful. Financial assistance can take the form of a caregiver allowance, as already implemented in some countries, to provide family members with the finances to stay at home to care for the PWD. Lowering or waiving the foreign domestic worker levy can also be considered.

Presently, there are over 150,000 foreign domestic maids in Singapore, amounting to 1 maid for every 6 households [24]. More than half (52.8\%) of our study population received assistance from a maid in caregiving. This remarkably high reliance on maids can be explained by several factors. Firstly, most of the foreign domestic maids come from Indonesia, Philippines and Myanmar, which have a lower standard of living and lower labor costs. The cost of employing a live-in domestic maid $(6,000$ USD per annum) is much lower compared to nurs- ing home placement (13,000 USD per annum) [25], making it a more viable option financially. The domestic maid not only frees the family caregiver to pursue gainful employment, but also provides respite and support for the family caregiver from the physical and psychological strain of caregiving, and assists in the household chores. Secondly, compared to Western countries, community care and support in the form of day care centers and home care services are still limited in our country, and are often costly. Therefore, the trend of employing foreign domestic maids to provide care for the PWD is likely continue, given the financial and practical advantages.

Although some studies have demonstrated the effectiveness of dementia day care services in delaying institutionalization [26], this was not apparent in our study. Compared to foreign domestic maids, dementia day care is a relatively less attractive option in our country due to its high cost, limited operating hours and the hassle of daily transport arrangements. Moreover, it is not uncommon that the PWD refuses to attend [27]. Nonetheless, structured day programs carry the potential benefits of a stimulating and engaging environment with increased opportunities for social interactions. A once or twice weekly day activity program can still be a useful adjunctive therapy to maintain quality of life in the PWD.

After the basic requirement of a dedicated caregiver has been met, interventions can then be directed at ameliorating caregiver stress and empowering caregivers with better coping skills to care well for the PWD. Re- 
search has shown that effective caregiver interventions are those which are multidimensional, encompassing education, skills training, family systems intervention, psychosocial support, counseling and use of technology [28], and are flexible enough to cater to the particular needs of caregiver-patient dyad as well. Early utilization of inhome help service to support caregivers at home has been shown to delay institutionalization [29]. Finally, the study findings have alluded to the importance of helping caregivers experience positive outcomes. A recent study identified the following factors to be associated with gains, namely maintaining caregiver mental well-being, use of positive caregiving strategies and participation in caregiver educational and support group programs [30]. This knowledge should be utilized in the design of interventions to facilitate caregiver gain and thereby increase the likelihood of maintaining the PWD at home. Based on the main findings of the study, we have derived a model (fig. 1) to provide a coherent understanding of how the goal of preventing institutionalization and maintaining PWD in their own homes can be achieved. Our study is valuable in that it is one of the few studies, in Asia in particular, to explore the factors associated with a caregiver's choice of institutional care for a relative with dementia. The finding of a protective effect of having foreign domestic maids care for PWD is unique and has not been reported in the literature. However, the study results should be taken in the context of its limitations.

First, being a cross-sectional study, we are unable to determine if the caregiver's preference at the point of study will translate into the eventual outcome. Second, the external validity and generalizability of the result may be limited given our sample characteristics. This was a self-selected population of caregivers who are educated and able to complete the questionnaires independently. The subjects were also more likely to be motivated caregivers who had been bringing the PWD for regular doctors' consults in the ambulatory dementia clinic or active participants of the local Alzheimer's association who had received the appropriate education and support. This may have inflated the proportion of caregivers who preferred in-home care. Finally, our sample population consisted largely of Chinese subjects. Given the importance of sociocultural factors on the outcomes related to dementia care, the perspectives of the Chinese caregivers cannot be directly extrapolated to that of the other ethnic groups.

\section{Conclusion}

Most families preferred to care for their loved ones with dementia at home rather than admit them to a nursing home. Those who chose to institutionalize the PWD did so primarily because there was no dedicated caregiver when the main caregiver was busy with work outside the home. For this reason, being able to employ a foreign domestic maid to care for the PWD is protective of institutionalization. Strategies to minimize nursing home placement must first address the pragmatic issue of providing a dedicated caregiver for the PWD. When such a person is in place, interventions to help caregivers cope with behavioral problems in the PWD and enhance caregiver gain can serve to sustain the caregiver through the rigors of caregiving.

\section{References}

1 Ferri CP, Prince M, Brayne C, et al: Global prevalence of dementia: a Delphi consensus study. Lancet 2005;366:2112-2117.

2 Asia Pacific Members of Alzheimer's Disease International: Dementia in the Asia Pacific region: the epidemic is here. Alzheimer's Disease International 2006; http://www.alz. co.uk/research/files/apreport.pdf (accessed May 25, 2010).

3 Speech by Mr. Khaw Boon Wan, Minister for Health, at the Ministry of Health Committee of Supply Debate on elderly care and support on 9-10 February 2009. http://www.pap. org.sg/articleview.php?id $=4444 \& \operatorname{cid}=84$ (accessed 25 May 2010).
4 Ann VS, Dee AJ, Norman JV: Opinions of people aged over 75 years on private and local authority residential care. Age Ageing 1989; 18:380-386.

5 Yeoh BS, Huang S: Foreign domestic worker and home-based care for elders in Singapore. J Aging Soc Policy 2010;22:69-88.

6 Caron CD, Ducharme F, Griffith J: Deciding on institutionalization for a relative with dementia: the most difficult decision for caregivers. Can J Aging 2006;25:193-205.

$\checkmark 7$ Yaffe K, Fox P, Newcomer R, Sands L, Lindquist K, Dane K, Covinsky KE: Patient and caregiver characteristics and nursing home placement in patients with dementia. JAMA 2002;287:2090-2097.
-8 Luppa M, Luck T, Brähler E, König HH, Riedel-Heller SG: Prediction of institutionalisation in dementia. A systematic review. Dement Geriatr Cogn Disord 2008;26:65-78.

$\checkmark$ Spruytte N, Van Audenhove C, Lammertyn F: Predictors of institutionalization of cognitively-impaired elderly cared for by their relatives. Int J Geriatr Psychiatry 2001;16:11191128.

10 Sanders S: Is the glass half empty or half full? Reflections on strain and gain in caregivers of individuals with Alzheimer's disease. Soc Work Health Care 2005;40:57-73.

11 Netto NR, Goh YNJ, Yap LKP: Growing and gaining through caring for a loved one with dementia. Dementia 2009;8:245-261. 
12 Gaugler JE, Duval S, Anderson KA, Kane RL: Predicting nursing home admission in the US: a meta-analysis. BMC Geriatrics 2007;7: 13.

13 American Psychiatric Association. Diagnostic and Statistical Manual of Mental Disorders, ed 4. Washington, American Psychiatric Association, 2000.

14 American Psychiatric Association. Diagnostic and Statistical Manual of Mental Disorders, ed 3. Washington, American Psychiatric Association, 1987.

$>15$ Yap P, Luo N, Ng WY, Chionh HL, Lim J, Goh J: Gain in Alzheimer care instrument (GAIN) - a new scale to measure caregiving gains in dementia. Am J Geriatr Psychiatry 2010;18:68-76.

16 Goldberg DP, Hillier VF: A scaled version of the General Health Questionnaire. Psychol Med 1979;9:139-145.

17 Fones CS, Kua EH, Ng TP, Ko SM: Studying the mental health of a nation: a preliminary report on a population survey in Singapore. Singapore Med J 1998;39:251-255.

18 Zarit SH, Reever KE, Peterson JB: Relatives of the impaired elderly: correlates of feelings of burden. Gerontologist 1980;20:649-655.
19 Seng BK, Luo N, Ng WY, Lim J, Chionh HL, Goh J, Yap P: Validity and reliability of the Zarit Burden Interview in assessing caregiving burden in Singapore. Ann Acad Med Singapore 2010, in press.

20 Vernooij-Dassen MJ, Felling AJ, Brummelkamp E, Dauzenberg MG, van den Bos GA, Grol R: Assessment of caregiver's competence in dealing with the burden of caregiving for a dementia patient: a Short Sense of Competence Questionnaire (SSCQ) suitable for clinical practice. J Am Geriatr Soc 1999;47:256-257.

21 Teri L, Truax P, Logsdon R, Uomoto J, Zarit S, Vitaliano PP: Assessment of behavioral problems in dementia: the revised memory and behavior problems checklist. Psychol Aging 1992;7:622-631.

22 Banerjee S, Murray J, Foley B, Atkins L, Schneider J, Mann A: Predictors of institutionalisation in people with dementia. J Neurol Neurosurg Psychiatry 2003;74:13151316.

23 Torti FM Jr, Gwyther LP, Reed SD, Friedman JY, Schulman KA: A multinational review of recent trends and reports in dementia caregiver burden. Alzheimer Dis Assoc Disord 2004;18:99-109.

24 Wong G: Singapore advocacy groups campaign 'Days Off' for maids. The Irrawady 2008; http://www.irrawaddy.org/article. php?art_id=11709 (accessed 25 May 2010).
25 Low TL: Ministry of Health Supplement on Nursing Home Charges 2007. http://www. moh.gov.sg (accessed 25 May 2010).

26 Robert SW, Judith JM, Yan L, Neelum TA, David WG, Denis AE: Nursing Home Placement, Day Care Use, and Cognitive Decline in Alzheimer's Disease. Am J Psychiatry 2007;164:910-915.

27 Durand M, James A, Ravishankar A, Bamrah JS, Purandare NB: Domiciliary and day care services: why do people with dementia refuse? Aging Mental Health 2009;13:414419.

28 Gitlin LN, Belle SH, Burgio LD, et al: Effect of multicomponent interventions on caregiver burden and depression: the REACH multisite initiative at 6-month follow-up. Psychol Aging 2003; 18:361-374.

29 Gaugler JE, Kane RL, Kane RA, Newcomer R: Early community-based service utilization and its effects on institutionalization in dementia caregiving. Gerontologist 2005;45: 177-185.

30 Liew TM, Luo N, Ng WY, Chionh HL, Goh J, Yap P: Predicting gains in dementia caregiving. Dement Geriatr Cogn Disord 2010;29: $115-122$. 